\title{
Model Generalized Poisson Regression (GPR) dan Penerapannya pada Angka Pengangguran bagi Penduduk Usia Kerja di Provinsi Sulawesi Selatan
}

\author{
Hisyam Ihsan $^{1, \text { a) }}$, Wahidah Sanusi ${ }^{1, b)}$, dan Risna Ulfadwiyanti ${ }^{1, c)}$ \\ ${ }^{1}$ Jurusan Matematika FMIPA Universitas Negeri Makassar, 90224 \\ a)hisyam.ihsan@unm.ac.id \\ b)wahidah.sanusi@unm.ac.id \\ c)risnaulfadwiyanti@gmail.com
}

\begin{abstract}
Abstrak. Penelitian ini membahas tentang pembentukan model Generalized Poisson Regression (GPR) dan penerapannya pada angka pengangguran bagi penduduk usia kerja di Provinsi Sulawesi Selatan. Jenis penelitian ini adalah penelitian terapan yang menggunakan model regresi nonlinear, yaitu model regresi Poisson dan model GPR. Variabel respon yang digunakan adalah jumlah angka pengangguran pada usia kerja yang termasuk angkatan kerja di Provinsi Sulawesi Selatan pada tahun 2017. Adapun variabelvariabel prediktor yang digunakan yaitu persentase angkatan kerja terhadap penduduk usia kerja, Indeks Pembangunan Manusia, persentase bekerja terhadap angkatan kerja, kepadatan penduduk, dan pertumbuhan ekonomi. Penelitian menggunakan metode Maximum Likelihood Estimation (MLE) untuk mengestimasikan parameter dan menghasilkan sebuah model GPR. Variabel prediktor yang memberikan pengaruh secara signifikan adalah Indeks Pembangunan Manusia dan persentase bekerja terhadap angkatan kerja.
\end{abstract}

Kata kunci: Angka Pengangguran, Regresi Poisson, Overdispersi, Generalized Poisson Regression, Maximum Likelihood Estimation

\begin{abstract}
This study discusses the formation of the Generalized Poisson Regression (GPR) model and its application to the unemployment rate for the working age population in South Sulawesi Province. This type of research is applied research that uses the Poisson regression model, namely Poisson regression and GPR models. The response variabel used is the total unemployment rate at working age which includes the workforce in South Sulawesi Province in 2017. The predictor variables used are the percentage of the workforce on the working age population, the Human Development Index, the percentage of work on the labor force, population density, and economic growth. This research uses the Maximum Likelihood Estimation (MLE) method to estimate parameters and produce a GPR model. The predictor variables which have a significant influence are the Human Development Index and the percentage of work on the labor force.
\end{abstract}

Keywords: Unemployment Rate, Poisson Regression, Overdispersion, Generalized Poisson Regression, Maximum Likelihood Estimation 


\section{PENDAHULUAN}

Analisis regresi adalah suatu metode yang digunakan untuk menganalisis hubungan antara variabel terikat dengan beberapa variabel bebas. Untuk menganalisis data variabel respon berupa data kontinu, umumya menggunakan analisis regresi. Namun dalam pengaplikasiannya, data variabel respon yang akan dianalisis juga dapat berupa data diskrit (data count) (Ruliana, 2015).

Salah satu model regresi adalah model regresi Poisson. Model ini dapat digunakan untuk menganalisis hubungan antara variabel terikat diskrit berupa data cacah (count) dengan variabel bebas berupa data diskrit, kontinu, kategorik atau campuran (Ruliana, 2015). Model regresi Poisson mensyaratkan equidispersi yaitu harus memenuhi asumsi bahwa nilai variansi dari variabel respon sama dengan nilai rata-ratanya (Cahyandari, 2014).

Dalam kenyataan di lapangan, sering terjadi pelanggaran asumsi equidispersi. Pelanggaran ini dapat berupa overdispersi atau underdispersi. Overdispersi terjadi apabila nilai variansi lebih besar dari nilai rata-rata sedangkan underdispersi terjadi apabila nilai variansnya lebih kecil dari nilai rata-rata (Wang \& Famoye, 1997). Overdispersi atau underdispersi dapat menyebabkan taksiran parameter yang diperoleh tidak efisien. Penggunaan regresi Poisson dapat berakibat fatal dalam interpretasi model karena dapat menaksir parameter standar error yang terlalu rendah. Hal ini dapat memberikan kesimpulan yang keliru tentang signifikan atau tidaknya parameter regresi yang terlibat (Darnah, 2011).

Penanganan model regresi untuk data diskrit pernah diteliti oleh Ismunarti, Azizah, dan Wasono (2011). Penelitian ini dilakukan dengan menggunakan regresi Poisson. Yulianingsih, Sukarsa dan Suciptawati (2012) juga melakukan penelitian tersebut untuk mengetahui faktor-faktor yang mempengaruhi jumlah siswa tidak lulus ujian nasional di Provinsi Bali untuk tingkat SMA/SMK. Namun, tidak semua data yang diteliti menggunakan regresi Poisson memenuhi asumsi equidispersi. Oleh karena itu Putra, Kencana, dan Srinadi (2013) melakukan penelitian dengan menerapkan Generalized Poisson Regression (GPR) untuk mengatasi fenomena overdispersi pada kasus regresi Poisson. Penelitian lain juga dilakukan oleh Cahyandari (2014) dengan melakukan pengujian overdispersi pada regresi Poisson, dan Rusianti (2016) dalam penelitiannya tentang penanganan data overdispersi menggunakan GPR.

Pada penelitian ini, kasus overdispersi regresi Poisson juga akan diatasi menggunakan model GPR. Model GPR merupakan bagian dari Generalized Linear Model (GLM) yang variabel dependennya tidak harus berdistribusi normal dan variansi untuk uji hipotesisnya tidak harus konstan (Famoye, 1993).

Penelitian ini mengkaji dan memodelkan permasalahan perekonomian khususnya pengangguran di Sulawesi Selatan. Sulawesi Selatan merupakan salah satu penyumbang tenaga kerja dengan persentase tingkat pengangguran mencapai $5,61 \%$ (BPS, 2017). Untuk menurunkan angka pengangguran, salah satu cara yang dapat dilakukan adalah dengan mengetahui penyebabnya. Dengan demikian, peneliti juga mengkaji faktor-faktor yang memberikan pengaruh signifikan terhadap angkapengangguran tersebut. Pendugaan koefisien parameter model yang digunakan adalah metode Maximum Likelihood Estimation (MLE). Untuk pemilihan model terbaik, peneliti menggunakan Akaike Information Criterion (AIC) dan Bayesian Schwartz Information Criteria (BIC).

\section{METODE PENELITIAN}

\section{Jenis dan Sumber Data}

Penelitian ini menggunakan data sekunder yang diperoleh dari Badan Pusat Statistik Provinsi Sulawesi Selatan. Data yang digunakan merupakan data angka pengangguran bagi penduduk usia kerja yang diasumsikan mengikuti distribusi Poisson. Adapun data lainnya berupa faktor-faktor 
yang diduga berpengaruh terhadap pertumbuhan angka pengangguran di Provinsi Sulawesi Selatan tahun 2017. Data ini diperoleh berdasarkan hasil Survey Sosial Ekonomi Nasional (SUSENAS) tahun 2016 dan data Sulawesi Selatan dalam Angka tahun 2018.

\section{Variabel Penelitian}

$\mathrm{Y}=$ Jumlah angka pengangguran (jiwa/orang)

$X_{1}=$ Persentase angkatan kerja terhadap penduduk usia kerja (\%)

$X_{2}=$ Indeks Pembangunan Manusia (\%)

$X_{3}=$ Persentase bekerja terhadap angkatan kerja (\%)

$X_{4}=$ Kepadatan Penduduk $\left(\frac{\text { orang }}{\mathrm{km}^{2}}\right)$

$X_{5}=$ Pertumbuhan Ekonomi (\%)

\section{Prosedur Penelitian}

1. Mengumpulkan data dan asumsikan berdistribusi Poisson

2. Mendeteksi hubungan multikolonieritas antara variabel prediktor

3. Menaksir parameter model regresi Poisson dengan menggunakan metode MLE.

Penaksiran parameter menggunakan metode MLE dapat dilakukan dengan langkah-langkah:

4. Melakukan pengujian parameter model regresi Poisson

5. Mendapatkan model regresi Poisson

6. Uji asumsi equidispersi

7. Menaksir parameter model GPR dengan MLE

8. Menguji signifikansi model GPR

9. Mendapatkan faktor-faktor yang mempengaruhi angka pengangguran bagi penduduk usia kerja di Provinsi Sulawesi Selatan.

10. Mendapatkan model GPR.

11. Memilih model terbaik

12. Pemilihan model terbaik dilakukan dengan melihat nilai AIC dan BIC. Model yang memiliki nilai AIC dan BIC terkecil merupakan model terbaik.

\section{HASIL DAN PEMBAHASAN}

\section{Estimasi Parameter Model GPR Menggunakan Metode MLE}

1) Membentuk fungsi Likelihood

$$
\begin{aligned}
L(\beta, \alpha, y) & =\prod_{i=1}^{n} P\left(y_{i}, \beta, \alpha\right) \\
L(\beta, \alpha ; y) & =\prod_{i=1}^{n}\left(\frac{e^{\left(\beta_{0}+\sum_{j=1}^{5} \beta_{j} x_{i j}\right)}}{1+\alpha e^{\left(\beta_{0}+\sum_{j=1}^{5} \beta_{j} x_{i j}\right)}}\right)^{y_{i}} \frac{\left(1+\alpha y_{i}\right)^{y_{i}-1}}{y_{i} !} \exp \left(-\frac{e^{\left(\beta_{0}+\sum_{j=1}^{5} \beta_{j} x_{i j}\right)\left(1+\alpha y_{i}\right)}}{1+\alpha e^{\left(\beta_{0}+\sum_{j=1}^{5} \beta_{j} x_{i j}\right)}}\right)
\end{aligned}
$$

2) Membentuk fungsi log likelihood dari fungsi likelihood yang telah diperoleh $L\left(\mu_{i}, y_{i}\right)=L=\ln L(\beta, \alpha, y)$

$L=\sum_{i=1}^{n}\left\{y_{i}\left(\beta_{0}+\sum_{j=1}^{5} \beta_{j} x_{i j}\right)-y_{i} \ln \left(1+\alpha e^{\left(\beta_{0}+\sum_{j=1}^{5} \beta_{j} x_{i j}\right)}\right)+\left(y_{i}-1\right) \ln \left(1+\alpha y_{i}\right)-\frac{e^{\left(\beta_{0}+\sum_{j=1}^{5} \beta_{j} x_{i j}\right)\left(1+\alpha y_{i}\right)}}{\left(1+\alpha e^{\left(\beta_{0}+\sum_{j=1}^{5} \beta_{j} x_{i j}\right)}\right)}-\ln \left(y_{i} !\right)\right\}$ 
3) Mendiferensialkan persamaan log-likelihood yang telah diperoleh

a. Mendiferensialkan persamaan terhadap $\beta_{0}$

$$
\frac{\partial l}{\partial \beta_{0}}=\sum_{i=1}^{n}\left\{\frac{y_{i}-e^{\left(\beta_{0}+\sum_{j=1}^{5} \beta_{j} x_{i j}\right)}}{\left(1+\alpha e^{\left(\beta_{0}+\sum_{j=1}^{5} \beta_{j} x_{i j}\right)}\right)^{2}}\right\}=0
$$

b. Mendiferensialkan persamaan terhadap $\beta_{j} ; j=1,2, \ldots, 5$

i) Terhadap $\beta_{1}$

$$
\frac{\partial l}{\partial \beta_{1}}=\sum_{i=1}^{n}\left\{\frac{y_{i} x_{i 1}-e^{\left(\beta_{0}+\sum_{j=1}^{5} \beta_{j} x_{i j}\right)} x_{i 1}}{\left(1+\alpha e^{\left(\beta_{0}+\sum_{j=1}^{5} \beta_{j} x_{i j}\right)}\right)^{2}}\right\}=0
$$

ii) Terhadap $\beta_{2}$

$$
\frac{\partial l}{\partial \beta_{2}}=\sum_{i=1}^{n}\left\{\frac{y_{i} x_{i 2}-e^{\left(\beta_{0}+\sum_{j=1}^{5} \beta_{j} x_{i j}\right)} x_{i 2}}{\left(1+\alpha e^{\left(\beta_{0}+\sum_{j=1}^{5} \beta_{j} x_{i j}\right)}\right)^{2}}\right\}=0
$$

iii) Terhadap $\beta_{3}$

$$
\frac{\partial l}{\partial \beta_{3}}=\sum_{i=1}^{n}\left\{\frac{y_{i} x_{i 3}-e^{\left(\beta_{0}+\sum_{j=1}^{5} \beta_{j} x_{i j}\right)} x_{i 3}}{\left(1+\alpha e^{\left(\beta_{0}+\sum_{j=1}^{5} \beta_{j} x_{i j}\right)}\right)^{2}}\right\}=0
$$

iv) Terhadap $\beta_{4}$

$$
\frac{\partial l}{\partial \beta_{4}}=\sum_{i=1}^{n}\left\{\frac{y_{i} x_{i 4}-e^{\left(\beta_{0}+\sum_{j=1}^{5} \beta_{j} x_{i j}\right)} x_{i 4}}{\left(1+\alpha e^{\left(\beta_{0}+\sum_{j=1}^{5} \beta_{j} x_{i j}\right)}\right)^{2}}\right\}=0
$$

v) Terhadap $\beta_{5}$

$$
\frac{\partial l}{\partial \beta_{5}}=\sum_{i=1}^{n}\left\{\frac{y_{i} x_{i 5}-e^{\left(\beta_{0}+\sum_{j=1}^{5} \beta_{j} x_{i j}\right)} x_{i 5}}{\left(1+\alpha e^{\left(\beta_{0}+\sum_{j=1}^{5} \beta_{j} x_{i j}\right)}\right)^{2}}\right\}=0
$$

c. Mendiferensialkan persamaan terhadap $\alpha$

$$
\frac{\partial l}{\partial \alpha}=\sum_{i=1}^{n}\left\{-\frac{y_{i} e^{\left(\beta_{0}+\sum_{j=1}^{5} \beta_{j} x_{i j}\right)}}{1+\alpha e^{\left(\beta_{0}+\sum_{j=1}^{5} \beta_{j} x_{i j}\right)}}+\frac{y_{i}\left(y_{i}-1\right)}{1+\alpha y_{i}}-\frac{y_{i} e^{\left(\beta_{0}+\sum_{j=1}^{5} \beta_{j} x_{i j}\right)}-\left(e^{\left(\beta_{0}+\sum_{j=1}^{5} \beta_{j} x_{i j}\right)}\right)^{2}}{\left(1+\alpha e^{\left(\beta_{0}+\sum_{j=1}^{5} \beta_{j} x_{i j}\right)}\right)^{2}}\right\}=0
$$

Penaksiran parameter $\beta$ secara manual mengalami kesulitan karena hasilnya tidak eksak. Dengan demikian, penentuannya dilakukan menggunakan metode Newton Raphson dengan bantuan software statistika. Setelah penaksiran parameter selesai, estimasi model GPR-nya adalah:

$$
\widehat{y_{l}}=x_{i}^{T} \beta
$$

\section{Deskripsi Statistik}

Deskripsi statistik bertujuan untuk mengetahui karakteristik dari masing-masing variabel. Setiap variabel dideskripsikan dengan menggunakan banyaknya data, nilai minimum, nilai maksimum, nilai rata-rata, standar deviasi dan variansi sebagaimana Tabel 1.

TABEL 1. Deskripsi Statistik Kasus Pengangguran bagi Penduduk Usia Kerja di Provinsi Sulawesi Selatan

\begin{tabular}{ccrrrrr}
\hline Variabel & N & \multicolumn{1}{c}{ Min } & \multicolumn{1}{c}{ Max } & \multicolumn{1}{c}{ Mean } & \multicolumn{1}{c}{ Std. Deviasi } & \multicolumn{1}{c}{ Variansi } \\
\hline $\mathrm{Y}$ & 24 & 1337,00 & 64954,00 & 8903,9583 & 12623,94328 & 159363943,868 \\
$X_{1}$ & 24 & 49,17 & 77,70 & 62,8529 & 6,05053 & 36,609 \\
$X_{2}$ & 24 & 62,67 & 81,13 & 68,9796 & 4,17840 & 17,459 \\
$X_{3}$ & 24 & 89,04 & 98,13 & 95,0829 & 2,30572 & 5,316 \\
$X_{4}$ & 24 & 41,00 & 8471,00 & 638,2917 & 1693,44112 & 2867742,824 \\
$X_{5}$ & 24 & 3,07 & 8,43 & 7,1367 & 1,12746 & 1,271 \\
\hline
\end{tabular}




\section{Pemodelan Angka Pengangguran bagi Penduduk Usia Kerja di Provinsi Sulawesi Selatan}

\section{Uji Multikolinearitas}

Salah satu syarat yang harus dipenuhi dalam analisis regresi adalah tidak terjadi kasus multikolinieritas antarvariabel prediktor. Oleh karena itu, dilakukan uji multikolinearitas pada data yang diamati. Masalah multikolinearitas dapat dideteksi dengan melihat nilai Tolerance atau nilai Variance Inflation Factor (VIF) data yang diamati.

$H_{0}$ : Model regresi memiliki masalah multikolinieritas

$H_{1}$ : Model regresi tidak memiliki masalah multikolinieritas

Taraf signifikansi yang digunakan adalah $\alpha=0,05$

TABEL 2. Nilai Tollerance dan VIF Setiap Variabel Prediktor

\begin{tabular}{ccc}
\hline \multirow{2}{*}{ Variabel } & \multicolumn{2}{c}{ Collinearity Statistic } \\
\cline { 2 - 3 } & Tolerance & VIF \\
\hline$X_{1}$ & 0,913 & 1,096 \\
$X_{2}$ & 0,358 & 2,794 \\
$X_{3}$ & 0,516 & 1,939 \\
$X_{4}$ & 0,417 & 2,399 \\
$X_{5}$ & 0,721 & 1,386 \\
\hline
\end{tabular}

Kriteria uji yang digunakan adalah tolak $H_{0}$ jika seluruh variabel prediktor memiliki $V I F<10$ dan Tolerance $>0,1$. Sebaliknya jika seluruh variabel prediktor memiliki $V I F>10$ dan Tolerance $>0,1$ maka $H_{0}$ diterima.

Berdasarkan Tabel 2, diperoleh nilai Tolerance tiap variabel prediktor lebih besar dari 0,1 dan nilai VIF untuk tiap variabel lebih kecil dari 10 . Hal ini berarti tidak ada keterkaitan hubungan antarvariabel prediktor. Dengan kata lain, tidak terjadi kasus multikolinearitas pada data yang diamati sehingga analisis data menggunakan model regresi dapat dilanjutkan.

\section{Pemodelan Regresi Poisson}

\section{Model Regresi Poisson}

Bentuk umum dari model Regresi Poisson yaitu:

$$
y_{i}=\mu_{i}+\varepsilon_{i}=\exp \left(\beta_{0}+\beta_{1} x_{1 i}+\beta_{2} x_{2 i}+\cdots+\beta_{p} x_{1 p}\right)+\varepsilon_{i}
$$

Langkah selanjutnya yang akan dilakukan adalah memodelkan faktor-faktor yang mempengaruhi jumlah angka pengangguran usia kerja.

\section{Estimasi Parameter Model Regresi Poisson}

Untuk melakukan pomedelan, terlebih dahulu akan dicari nilai estimasi parameter $\beta_{1}, \beta_{2}, \beta_{3}$, $\beta_{4}$, dan $\beta_{5}$. Hasil estimasi untuk masing-masing parameter $\beta$ ditunjukkan pada Tabel 3.

TABEL 3. Hasil Estimasi Parameter Model Regresi Poisson

\begin{tabular}{crr}
\hline Parameter & Estimasi & Standar Error \\
\hline (Konstan) & 38,6932 & 0,2142 \\
$\beta_{1}$ & $-0,0200$ & 0,0005 \\
$\beta_{2}$ & $-0,1133$ & 0,0011 \\
$\beta_{3}$ & $-0,2165$ & 0,0016 \\
$\beta_{4}$ & 0,0003 & 0,0000 \\
$\beta_{5}$ & $-0,0629$ & 0,0033 \\
\hline
\end{tabular}




\section{Pengujian Parameter Model Regresi Poisson}

Setelah mendapatkan hasil estimasi parameter, maka selanjutnya akan dilakukan pengujian parameter menggunakan uji Wald. Pengujian ini bertujuan untuk mendapatkan variabel prediktor yang berpengaruh signifikan terhadap variabel respon.

$$
\begin{array}{ll}
H_{0}: \beta_{j}=0 ; & j=1,2, \ldots, 5 \\
H_{1}: \beta_{j} \neq 0 ; & j=1,2, \ldots, 5
\end{array}
$$

Taraf signifikansi yang digunakan adalah $\alpha=0,05$

TABEL 4. Hasil Uji Parameter Model Regresi Poisson

\begin{tabular}{cr}
\hline Parameter & Wald Chi-Square \\
\hline (Konstan) & 32637,2 \\
$\beta_{1}$ & 1666,69 \\
$\beta_{2}$ & 10860,1 \\
$\beta_{3}$ & 18030,9 \\
$\beta_{4}$ & 30968,1 \\
$\beta_{5}$ & 373,67 \\
\hline
\end{tabular}

Kriteria uji yang digunakan adalah tolak $H_{0}$ jika nilai dari uji Wald lebih besar dari nilai $X^{2}{ }_{(0.05,1)}$. Berdasarkan Tabel Chi-square dengan tingkat signifikansi 0,05 dan derajat bebas 1 diperoleh nilai $\mathrm{X}^{2}{ }_{(0.05,1)}=3,8415$ sehingga dapat dijelaskan bahwa setiap variabel prediktor yang diamati memiliki pengaruh signifikan terhadap variabel respon.

Model angka pengangguran menggunakan Regresi Poisson dapat dituliskan sebagai berikut:

$$
y=\exp \left(386932-0,0200 x_{1}-0,1133 x_{2}-0,2165 x_{3}+0,0003 x_{4}-0,0629 x_{5}\right)
$$

Uji Kesesuaian (Goodness of Fit) Model Regresi Poisson

Uji kesesuaian model digunakan untuk mengetahui apakah model Regresi Poisson sudah layak atau sesuai dengan data yang diamati atau tidak.

$H_{0}=$ Sampel berasal dari populasi yang berdistribusi Poisson

$H_{1}=$ Sampel tidak berasal dari populasi yang berdistribusi Poisson

Taraf signifikansi yang digunakan adalah $\alpha=0,05$

TABEL 5. Kriteria Uji Kesesuaian (Goodness of Fit) Model Regresi Poisson

\begin{tabular}{lccc}
\hline \multicolumn{1}{c}{ Kriteria } & Db & Nilai & Nilai/Db \\
\hline Deviance & 18 & 26228,2497 & 1457,1250 \\
Pearson Chi-Square & 18 & 29857,8409 & 1658,7689 \\
\hline
\end{tabular}

Kriteria uji yang digunakan adalah tolak $H_{0}$ pada taraf signifikansi $\alpha$, jika $D>\chi^{2}{ }_{(18,0,05)}$.

Pada Tabel 5 diperoleh nilai Pearson Chi-Square > Deviance yaitu1658,7689 > 1457,1250. Hal ini berarti model yang didapatkan sudah sesuai dengan data yang diamati. Uji ini didasarkan pada seberapa sesuai frekuensi pengamatan yang diperoleh data sampel dengan frekuensi harapan yang diperoleh dari distribusinya.

\section{Uji Asumsi Equidispersi}

Pemeriksaan model Regresi Poisson dengan melakukan uji asumsi equidispersi dilakukan untuk mengecek apakah data tersebut memenuhi asumasi equidispersi. Asumsi equidispersi dapat dilihat dari nilai mean dan variansinya. Pada Tabel 1 dapat diketahui bahwa nilai mean dari variabel Y adalah 8903,9583 dengan variansi 159363943,868. Kedua kriteria tersebut bernilai lebih dari 1 yang menunjukkan terjadinya kasus overdispersi. Dengan demikian, asumsi equidispersi tidak terpenuhi. 


\section{Pemodelan GPR}

\section{Model GPR}

Pemodelan GPR dilakukan sebagai tindak lanjut penanganan kasus overdispersi pada model Regresi Poisson yang sebelumnya telah didapatkan.

\section{Estimasi Parameter GPR}

Untuk melakukan pomedelan maka terlebih dahulu akan dicari nilai estimasi parameter $\beta_{1}, \beta_{2}$, $\beta_{3}, \beta_{4}$, dan $\beta_{5}$. Hasil estimasi untuk masing-masing parameter $\beta$ ditunjukkan pada Tabel 6 .

TABEL 6. Hasil Estimasi Parameter Model GPR

\begin{tabular}{crr}
\hline Parameter & Estimasi & Standar Error \\
\hline (Konstan) & 45,3539 & 7,5328 \\
$\beta_{1}$ & $-0,01166$ & 0,01476 \\
$\beta_{2}$ & $-0,09069$ & 0,04010 \\
$\beta_{3}$ & $-0,3039$ & 0,07995 \\
$\beta_{4}$ & 0,000174 & 0,000154 \\
$\beta_{5}$ & $-0,1103$ & 0,07216 \\
\hline
\end{tabular}

\section{Pengujian Parameter Model GPR}

Setelah mendapatkan hasil estimasi parameter, maka selanjutnya akan dilakukan pengujian parameter menggunakan uji Wald. Pengujian ini bertujuan untuk mendapatkan variabel prediktor yang berpengaruh signifikan terhadap variabel respon.

$H_{0}: \beta_{j}=0 ; \quad j=1,2, \ldots, 5$

$H_{1}: \beta_{j} \neq 0 ; \quad j=1,2, \ldots, 5$

TABEL 7. Hasil Uji Parameter Model GPR

\begin{tabular}{cr}
\hline Parameter & Wald Chi-Square \\
\hline (Konstan) & 36,2507 \\
$\beta_{1}$ & 0,624057 \\
$\beta_{2}$ & 5,114817 \\
$\beta_{3}$ & 14,44856 \\
$\beta_{4}$ & 1,276607 \\
$\beta_{5}$ & 2,336458 \\
\hline
\end{tabular}

Kriteria uji yang digunakan adalah tolak $H_{0}$ jika nilai dari uji Wald lebih besar dari nilai $X^{2}{ }_{(0.05,1)}$ Berdasarkan Tabel Chi-square dengan tingkat signifikansi 0,05 dan derajat bebas 1 diperoleh nilai $\mathrm{X}^{2}{ }_{(0.05,1)}=3,8415$ sehingga dapat dijelaskan bahwa variabel prediktor yang memiliki pengaruh signifikan terhadap variabel respon adalah $X_{2}$ dan $X_{3}$.

Model angka pengangguran menggunakan GPR dapat dituliskan sebagai berikut:

$$
\hat{y}=\exp \left(45,3539-0,01166 x_{1}-0,09069 x_{2}-0.3039 x_{3}+0,000174 x_{4}-0,1103 x_{5}\right)
$$

\section{Uji Kesesuaian (Goodness of Fit) Model GPR}

Sama halnya pengujian pada model Regresi Poisson, uji kesesuaian pada model GPR ini digunakan untuk mengetahui apakah model sudah layak atau sesuai dengan data yang diamati atau tidak.

Oleh karena parameter model yang telah dihasilkan dari estimasi parameter belum tentu mempunyai pengaruh yang signifikan terhadap model, maka pengujian dilakukan dengan menggunakan statistik uji sebagai berikut. 
$H_{0}: \beta_{1}=\beta_{2}=\cdots=\beta_{p}=0$

$H_{1}: \exists \beta_{j} \neq 0 ; \quad j=1,2, \ldots, p$

TABEL 8. Kriteria Uji Kesesuaian (Goodness of Fit) Model GPR

\begin{tabular}{ll}
\hline \multicolumn{1}{c}{ Kriteria } & Nilai \\
\hline -2 Log Likelihood & 443,9 \\
AIC (smaller is better) & 457,9 \\
AICC (smaller is better) & 464,9 \\
BIC (smaller is better) & 466,1 \\
\hline
\end{tabular}

Kriteria uji yang digunakan adalah tolak $H_{0}$ apabila $G>X^{2}{ }_{(7,0,05)}$ dengan $v$ adalah banyaknya parameter model.

Berdasarkan kriteria uji kesesuaian pada Tabel 8 diperoleh nilai $G_{\text {hitung }}=443,9$ sedangkan berdasarkan Tabel Chi-square dengan tingkat signifikansi 0,05 dan derajat bebas 1 diperoleh nilai $\mathrm{X}_{(7,0.05)}^{2}=3,8415$. Dengan demikian, dapat dijelaskan bahwa nilai $G_{\text {hitung }}>\mathrm{X}^{2}{ }_{(7,0.05)}$ yang berarti bahwa model yang diperoleh telah sesuai dengan data yang ada.

\section{Pemilihan Model Terbaik}

Untuk menentukan model yang terbaik, disajikan nilai estimasi, standar error, dan kriteria model tiap variabel pada Tabel 9 berikut.

TABEL 9. Estimasi, Standar Error, dan Kriteria Model

\begin{tabular}{cccrr}
\hline \multirow{2}{*}{ Variabel } & \multicolumn{2}{c}{ Regresi Poisson } & \multicolumn{2}{c}{ GPR } \\
\cline { 2 - 5 } & Estimasi & SE & Estimasi & \multicolumn{1}{c}{ SE } \\
\hline (Konstan $)$ & 386932 & 0,2142 & 453539 & 7,5328 \\
$X_{1}$ & $-0,0200$ & 0,0005 & $-0,01166$ & 0,01476 \\
$X_{2}$ & $-0,01133$ & 0,0011 & $-0,09069$ & 0,04010 \\
$X_{3}$ & $-0,2165$ & 0,0016 & $-0,3039$ & 0,07995 \\
$X_{4}$ & 0,0003 & 0,0000 & 0,000174 & 0,000154 \\
$X_{5}$ & $-0,629$ & 0,0033 & $-0,1103$ & 0,07216 \\
\hline AIC & 44764,9700 & 472,3 \\
BIC & 44772,0383 & 480,6 \\
\hline
\end{tabular}

Berdasarkan Tabel 9, dapat diketahui metode GPR lebih baik dari pada Regresi Poisson. Hal ini ditunjukkan oleh nilai Standard Error pada GPR mengalami peningkatan atau dengan kata lain under estimate yang terjadi pada Regresi Poisson telah diatasi, Selain itu, nilai AIC dan BIC GPR $<$ Regresi Poisson yakni 472,3 < 44764,9700 dan 480,6 < 44772,0383.

\section{KESIMPULAN}

1. Persamaan estimasi parameter model GPR dengan $j=1,2, \ldots, 5$ yaitu:

$$
L(\beta, \alpha ; y)=\prod_{i=1}^{n}\left(\frac{e^{\left(\beta_{0}+\sum_{j=1}^{5} \beta_{j} x_{i j}\right)}}{1+\alpha e^{\left(\beta_{0}+\sum_{j=1}^{5} \beta_{j} x_{i j}\right)}}\right)^{y_{i}} \frac{\left(1+\alpha y_{i}\right)^{y_{i}-1}}{y_{i} !} \exp \left(-\frac{e^{\left(\beta_{0}+\sum_{j=1}^{5} \beta_{j} x_{i j}\right)\left(1+\alpha y_{i}\right)}}{1+\alpha e^{\left(\beta_{0}+\sum_{j=1}^{5} \beta_{j} x_{i j}\right)}}\right)
$$

Setelah estimasi parameter selesai, estimasi model GPR-nya adalah:

$$
\widehat{y_{l}}=x_{i}^{T} \beta
$$

2. Setelah melakukan analisis data dengan model Regresi Poisson, terjadi kasus overdispersi sehingga penelitian dilanjutkan dengan memanfaatkan model GPR dan diperoleh model sebagai berikut:

$$
\hat{y}=\exp \left(45,3539-0,01166 x_{1}-0,09069 x_{2}-0.3039 x_{3}+0,000174 x_{4}-0,1103 x_{5}\right)
$$


Variabel prediktor yang memberikan pengaruh secara signifikan adalah variabel Indeks Pembangunan Manusia $\left(X_{2}\right)$ dengan nilai parameter 0,09069 dan persentase bekerja terhadap angkatan kerja $\left(X_{3}\right)$ dengan nilai parameter 0,3039 .

\section{DAFTAR PUSTAKA}

BPS. (2017). Keadaan Poisson dengan Generalized Poisson I. Jurnal Eksponensial, 2(2). 5-10

Famoye, F. (1993). Restricted Generalized Poisson Regression Model Comm. Satist.Theor.\&Math, 22(5). 1335-1354.

Ismunarti, D.H., R. Azizah, \& R. Wasono. (2011). Analisis Regresi Poisson untuk Menjaga Hubungan Kelimpahan Makrobenthos dengan Parameter Perairan. Prosiding Seminar Nasional Statistika. Semarang, Indonesia: Universitas Diponegoro.

Putra, I. Y. E., Kencana, I. E., \& Srinadi, I. A. (2013). Penerapan Regresi Generalized Poisson untuk Mengatasi Fenomena Overdispersi pada Kasus Regresi Poisson. E-Jurnal Matematika Universitas Udayana Bali, 2(2). 49-53.

Ruliana. (2015). Pemodelan Generalized Poisson Regression (GPR) untuk Mengatasi Pelanggaran Equidispersi pada Regresi Poisson Kasus Campak di Kota Semarang (Skripsi). Universitas Negeri Semarang, Semarang.

Rusianti. (2016). Penanganan Data Overdispersi Menggunakan Regresi Poisson Tergeneralisir (Kasus Persentase Kematian Ibu Di Provinsi Sulawesi Tenggara 2012) (Skripsi). Universitas Haluoleo, Kendari.

Wang, W. \& Famoye, F. (1997). Modeling Household Fertility Decision With Generalized Poisson Regression. Journal of Population Economics, 10(3). 273-283.

Yulianingsih, K. A., Sukarsa, K. G., \& Suciptawati, L. (2012). Penerapan Regresi Poisson untuk Mengetahui Faktor-faktor yang Mempengaruhi Jumlah Siswa SMA/SMK yang Tidak Lulus UN di Bali. E-Jurnal Matematika Universitas Udayana, 1(1). 59-63. 